\title{
Numerical modelling of the effect of the hydro-kinetic turbines on the transport of sediments - Application to the Rhone site.
}

\author{
Khaled F (1), Guillou S (1), Hadri F (2) and Méar Y (1)
}

(1) University Laboratory of Applied Sciences of Cherbourg, university of Caen Normandy, 60 rue Max Pol Fouchet, CS 20082, 50130 Cherbourg en Cotentin, France

(2) LISV, 10-12 avenue de 1'Europe, 78140 Vélizy, France

Interest in electricity generation from low carbon technologies and renewable energy has become recently the most discussed concern. The need of sustainable, predictable energy generation has led in recent years to the development of Stream Turbines (ST) and has become a near reality, to reach $20 \%$ from the total energy production in France on 2020. Determining the impact of ST on their environment is becoming a significant interest nowadays. Regional modeling with a representation of the turbines' array with bed friction or momentum sink approach were proposed to quantify the impacts far away from the turbines. Sanchez and al. (2014) have studied the flow changes around a farm of stream turbines operated in Ria de Ortigueira. They concluded that the flow modifications were concentrated at local scale. While Fairley and al. (2015) found that, a farm of ST does not have remarkable effects on the baseline morphodynamics of sandbanks at regional scale. The energy extracted by the turbine will alter the hydrodynamics of the stream by increasing or reducing the friction in areas around the turbines. The present contribution investigates further the impact of the deployment of riverine turbines on the variation of the sandy bed at local scale. The aim is to provide prediction of the evolution caused by multiple stream turbines.

The first part of study is dedicated to represent the turbine, by a momentum source, without the sandy bed, using first the Actuator Disk, then the Blade Element Momentum Theory (BEMT) to determine the effects of hydrodynamic blades efforts (Shives et al.2016). The second part is dedicated to study the transport of sands affected by the turbine. The mixture of water and sediment is modeled by an Euler-Euler two-phase flow approach (Zhen Cheng et al. 2016), it involves one phase as a granular phase which is treated as a continuum one such as the sediment phase. The open source CFD software package OpenFOAM (Field Operation And Manipulation) is used in this study. The numerical results are validated with experimental measures of Mycek and al. 2014 for the BEMT (figure I), and with Pham Van Bang et al. 2006's measures for sedimentation processes (figure II).

In terms of perspectives, the validated models have been used to study the evolution of the bed level and the dynamic processes of sedimentation near an optimized farm of turbines.

Keywords: Stream Turbines, environmental impact, mobile sediment bed, numerical simulations, Euler-Euler Two-phase modelling, OpenFOAM solver 

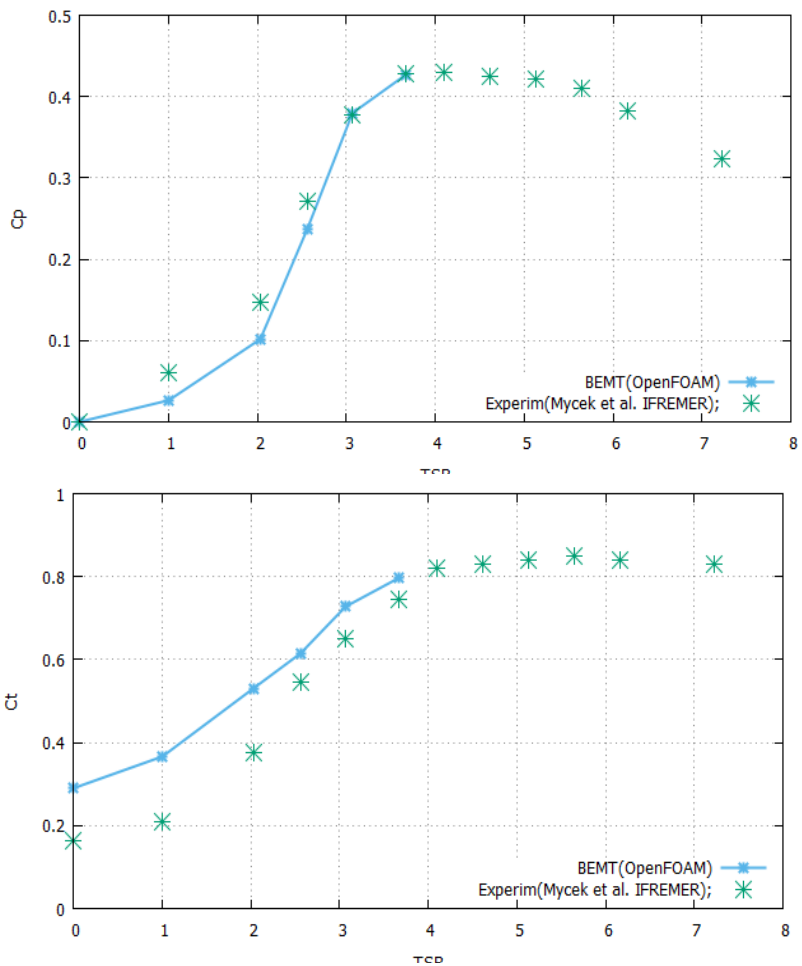

Figure I : Comparison between numerical (BEMT) and experimental (Mycek) results for: power (above) and thrust coefficients (below)

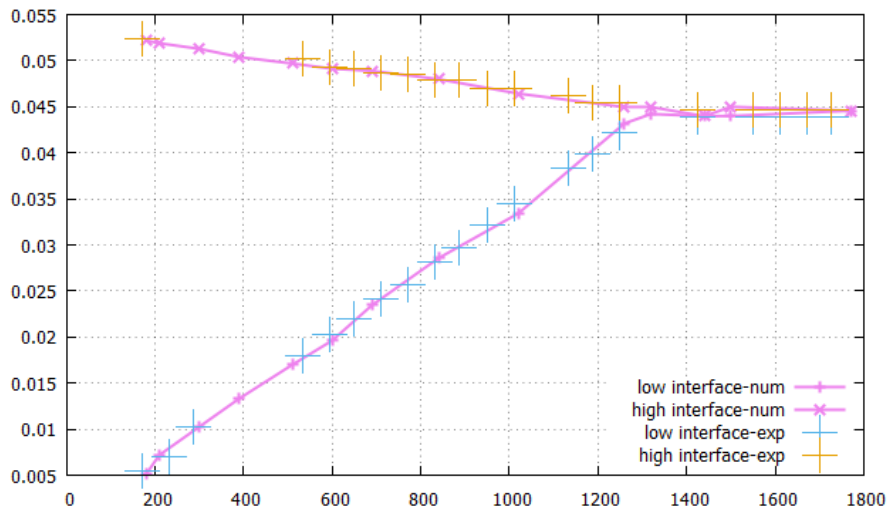

Figure II : Comparison of two-phase Euler model results with experiments of Pham Van Bang et al. (2008): evolution of the lower and upper interface positions between sediments and fluid in time. 


\section{References:}

M. Sánchez, R. Carballo, V. Ramos, G. Iglesias, Tidal stream energy impact on the transient and residual flow in an estuary: A 3D analysis, Applied Energy, Volume 116, 2014, Pages 167-177.

Fairley I., Masters I., Karunarathna H. (2015), The cumulative impact of tidal stream turbine arrays on sediment transport in the Pentland Firth, Renewable Energy, Volume 80, Pages 755-769.

Shives, Michael \& Crawford, Curran, 2016.Adapted two-equation turbulence closures for actuator disk RANS simulations of wind \& tidal turbine wakes. Renewable Energy, Elsevier, vol. 92(C), pages 273-292.

Zhen Cheng, Tian-Jian Hsu, Joseph Calantoni, SedFoam: A multi-dimensional Eulerian two-phase model for sediment transport and its application to momentary bed failure.

Paul Mycek, Benoît Gaurier, Grégory Germain, Grégory Pinon, Elie Rivoalen,Experimental study of the turbulence intensity effects on marine current turbines behaviour. Part I: One single turbine

Pham Van Bang, D., Lefrançois, E., Sergent, P., Bertrand, F. (2008). MRI experimental and finite elements modelling of the sedimentation-consolidation of mud. 